\title{
Are women and men well informed about fertility? Childbearing intentions, fertility knowledge and information-gathering sources in Portugal
}

Teresa Almeida-Santos ${ }^{1,2}$, Cláudia Melo ${ }^{3}$, Ana Macedo $^{4}$ and Mariana Moura-Ramos ${ }^{3^{*}}$ (1)

\begin{abstract}
Background: The postponement of parenthood may increase the number of couples experiencing infertility and prolonged time to pregnancy. Previous research has revealed that childless people are not well informed regarding fertility, which may threat their childbearing intentions. This study aimed to examine fertility knowledge and childbearing intentions held by Portuguese people and their use and perceived usefulness of information sources on fertility.
\end{abstract}

Methods: Participants were recruited using a random-route domiciliary approach. A total of 2404 individuals aged 18-45 were asked to complete a structured questionnaire evaluating socio-demographic characteristics, childbearing intentions, fertility knowledge and information-gathering sources regarding fertility.

Results: In total, $95.5 \%$ of the participants indicated the desire to have children in the future, and $61.7 \%$ reported that having children would contribute to life satisfaction. Most of the participants expressed the desire to have two children in the future. The discrepancy between the numbers of planned and desired children was higher in men, in participants with lower education levels, in professionally active participants and in the unemployed participants. Relationship stability seemed to be more important in influencing childbearing decisions than financial stability or family support. Participants' knowledge regarding fertility was poor. Women, the participants who were older than 25 , the participants with longer education and the participants with higher income exhibited the greatest levels of knowledge of fertility, although this knowledge was only slightly enhanced in these subgroups. Also, the participants overestimated both the chances of spontaneous pregnancy and the success rates of assisted reproduction techniques. Finally, the results revealed that websites were the main information sources used by the participants and only $18.0 \%$ of the participants had previously discussed fertility issues with their doctors.

Conclusions: Although Portuguese men and women reported the desire to have children in the future, their knowledge regarding fertility and infertility risk was poor. In addition, participants used more general sources of information, such as website, but not specialized sources, such as their doctors. There is a real need to work with general practitioners to empower them to provide adequate fertility information to every childless patient.

Keywords: Fertility knowledge, Childbearing intentions, Information, Fertility protection

\footnotetext{
* Correspondence: marianamr@fpce.uc.pt

${ }^{3}$ CINEICC - Cognitive and Behavioural Centre for Research and Intervention,

Faculty of Psychology and Educational Sciences, University of Coimbra, Rua

do Colégio Novo, 3001-802 Coimbra, Portugal

Full list of author information is available at the end of the article
}

(c) The Author(s). 2017 Open Access This article is distributed under the terms of the Creative Commons Attribution 4.0 International License (http://creativecommons.org/licenses/by/4.0/), which permits unrestricted use, distribution, and reproduction in any medium, provided you give appropriate credit to the original author(s) and the source, provide a link to the Creative Commons license, and indicate if changes were made. The Creative Commons Public Domain Dedication waiver (http://creativecommons.org/publicdomain/zero/1.0/) applies to the data made available in this article, unless otherwise stated. 


\section{Plain English Summary}

The postponement of parenthood may increase the number of couples experiencing infertility and prolonged time to pregnancy. In this study, we aimed to examine fertility knowledge and childbearing intentions held by Portuguese people and their use and perceived usefulness of information sources on fertility. Participants were 2404 individuals aged 18-45 who were asked to complete a structured questionnaire evaluating socio-demographic characteristics, childbearing intentions, fertility knowledge and information-gathering sources regarding fertility. In total, 95.5\% of the participants indicated the desire to have children in the future, and $61.7 \%$ reported that having children would contribute to life satisfaction. Most of the participants expressed the desire to have two children in the future, but we found a discrepancy between the number of desired and planned children. This discrepancy was higher in men, in participants with lower education levels, in professionally active participants and in the unemployed participants. We also found that participants' knowledge regarding fertility was poor. Women, the participants who were older than 25, the participants with longer education and the participants with higher income exhibited the greatest levels of knowledge of fertility, although this knowledge was only slightly enhanced in these subgroups. In addition, participants used more general sources of information, such as website, but not specialized sources, such as their doctors. Our results confirmed that there is a real need to work with general practitioners to empower them to provide adequate fertility information to every childless patient.

\section{Background}

For several decades, people across Europe have been postponing parenthood. As a consequence, an increasing number of couples are experiencing infertility and prolonged time to pregnancy. Assisted reproductive technology (ART) cannot fully compensate for the loss of fecundity that is linked to greater maternal age.

Fertility knowledge in the general population is poor. The evidence indicates that people are unaware of the biological aspects of conception and often overestimate the chances of achieving pregnancy at the time of ovulation [1]. People are also generally not well informed of when women are most fertile and lack understanding of the decline that occurs in female fertility after the age of 34 years [2]. Knowledge about the specific risk factors associated with decreased fertility is limited (e.g., sexually transmitted infections, smoking, alcohol consumption) [3] and erroneous with regard to factors that have no impact on fertility potential. It has been reported that women of reproductive age have insufficient fertility knowledge and awareness, with the primary areas of limited awareness being reproductive lifespan and assisted reproduction $[4,5]$.

Women have an acceptable understanding concerning age-associated declines in fertility but an overestimated belief in the success of assisted human reproductive treatments. Previous studies of Swedish [6], Finnish [4], American [7] British [3], Israeli [8] and Canadian [9, 10] university students have reported gaps in awareness of female infertility risk factors and an overestimation of the fertility of women in their late thirties. Studies from Sweden and Canada have shown that the understanding of female fertility among university students is deficient, especially the understanding of when female fertility declines and how this affects the chances of achieving pregnancy $[1,2,11]$.

A survey that addressed some of these issues by sampling a nationally representative group of female Canadians indicated that women were only moderately knowledgeable about fertility [9].

Several studies have identified a substantial need to inform health professionals and the general public about the increased reproductive risks that are associated with increased maternal age. Provision of this information is essential to enable those who desire to become parents to make informed decisions regarding when to start having children [12]. However, the interplay between the biological, psychological, relational, and social dimensions of fertility decision-making and the realization of fertility intentions are complex processes.

Most young people in Europe want to have two or more children, with an average of 2.2 children. The mean difference between the intended and realized family size is called the fertility gap and was estimated to be 0.34 children per woman in the European Union in 2006, ranging from 0.25 in Germany and Austria to 0.71 in Northern Europe [13]. The fertility gap is generally related to personal or socio-economic factors that delay the start of childbearing. Such factors may include not having met a suitable partner, being in a broken relationship, having financial constraints, and or having competing educational, professional or personal ambitions [14]. Consequently, many couples experience tension between the desire to have children and their reasons for delaying childbearing.

Regardless of the trend of delaying childbearing, both women and men consider the late twenties the ideal time for having children. A study of a Canadian population conducted by Daniluk and Koert [9] showed that men believe the ideal age for having a first child is 29.5 years, although most do not expect to become parents before the age of 36.8 years. Women indicated that 26.8 years is the ideal age for having a first child, but most do not expect to have their first child before the age of 32.4 years [9]. 
Sub-optimal fertility behaviour may be influenced by attitudes towards fertility medical consultation and treatments, especially if it prevents people from seeking help. To date, most studies of fertility have focused on university students, and used online data collection methods. This focus on highly educated and well informed participants threatens the generalizability of their conclusions to the childbearing population aged between 25 and 40 years old or to less educated people. To expand current knowledge, the primary aims of the present study were to examine fertility knowledge and intentions in men and women not trying to conceive and to ascertain whether these varied across gender and contextual factors and to examine which sources of information are used to gather information about fertility. To achieve these goals, we surveyed 2400 childless individuals ranging in age from 18 to 45 years old, using a national representative sample and face-to-face data collection method to overcome limitations of the previous studies reported above. Based on the research reviewed above, we hypothesized that women with higher educational levels, those who previously engaged in medical consultations and those with higher socio-economic status would have better fertility knowledge and more favourable beliefs about treatment than other populations.

\section{Methods}

\section{Procedures}

This study was submitted to the Portuguese Data Protection Ethics Commission. The study used a crosssectional design to evaluate a nationally representative sample, which was calculated separately for women and men stratified by region and age group. The final sample size was calculated using a 2:1 female-male ratio and assuming e a $2.5 \%$ error margin for women and a $3.5 \%$ error margin for men, for a $95 \%$ confidence interval (assuming the female population as the primary objective). Data were collected between August and December 2014 using a random-route domiciliary approach., i.e. for each randomly-chosen sampling points, interviewers were assigned with a starting location and provided with instructions on the random-route procedures and the selection of respondents, and the routes ended when the predefined number of respondents was achieved. This approach was considered once the probability of the selected respondents is unknown [15]. Diaz de Rada and Martínez Martín compared random-route sampling with two probabilities samples and reported that the randomroute samples provide a better degree of representativeness [16]. The data collection period spanned Monday to Sunday from 10:00 to 21:00. Data were collected using a structured questionnaire, which was administered by team members trained in data collection, in ethical and data privacy, and in technical issues specific to this study. All participants gave oral informed consent prior to participation in the study. The refusal rate for answering was $20 \%$. The questionnaire evaluated sociodemographic characteristics, childbearing intentions, fertility knowledge and information-gathering sources regarding fertility.

\section{Participants}

The study sample included 2404 childless Portuguese women $(n=1596 ; 66.4 \%)$ and men $(n=808,33.6 \%)$ aged between 18 and 45 years old and living in Continental Portugal. Individuals undergoing fertility treatments at the time of data collection were excluded.

\section{Measures}

The questionnaire used in the study covered three main topics:

\section{Childbearing intentions}

This section assessed the participants' childbearing intentions regarding 1) the numbers of desired and intended children, 2) the ideal age to have a first and last child, 3) the intended age to have a first child, 4) the importance of parenthood in life satisfaction, and 5) the experienced motives for and barriers toward parenthood. The importance of parenthood in life satisfaction was assessed using a Likert-type scale that ranged from 1 (not important) to 5 (very important). Motives for parenthood were assessed using a Likert-type scale that ranged from 1 (not valued) to 5 (highly valued). The following 4 motives were assessed: socioeconomic values (e.g., social pressure and social value), personal fulfilment (e.g., to provide meaning to life), continuity (e.g., to assure familial continuity), and marital relationship (e.g., to strengthen a marital relationship). Barriers/facilitating factors for childbearing were assessed by asking what factors (e.g., economic stability, martial relationship stability and family support) would be essential for deciding to have children in the future. Responses were provided using a Likert-type scale that ranged from 1 (not important) to 5 (very important).

\section{Knowledge of fertility}

This section consisted of 24 statements (e.g., "A 40-yearold woman has similar odds to a 30-year-old woman for achieving pregnancy", "If a woman is obese, this may affect odds of achieving a pregnancy"), and the participants were asked to score each as true or false. Correct answers were scored as 1, and incorrect answers were scored as 0 . If a participant failed to provide an answer, then the statement was coded as incorrect (0). Knowledge of fertility and of infertility risk factors was calculated by summing all the answers. 


\section{Information gathering about fertility issues}

The participants were asked about what sources they used to gather information about fertility (each source was coded 0 for not used and 1 for used) and how useful they considered them to be. The list of sources included media, family and friends, and physicians. The list was also evaluated using a Likert-type scale that ranged from 1 (not useful) to 5 (very useful). In addition, specific questions were asked regarding information provided by general practitioners.

\section{Data analysis}

Data were analysed using IBM SPSS, version 20.0 (IBM Corporation, Armonk, NY, USA). Power calculations demonstrated that the achieved sample size was sufficient to detect small effects for analysis with a power of .90 (G*Power). The significance level was set at 0.05 . Comparisons between subgroups of participants were conducted using analysis of variance (ANOVA) with Bonferroni post hoc analysis. ANOVA for repeated measures was used to evaluate discrepancies between behavioural intentions and desires and planned behaviour.

\section{Results}

\section{Description of participants}

The main socio-demographic characteristics of the participants are reported in Table 1.

The study participants included both men and women around 32 years old. Most participants had completed secondary education and were employed. The majority

Table 1 Participants' characteristics

\begin{tabular}{llll}
\hline & $\begin{array}{l}\text { Women }(n=1596 ; \\
66.4 \%)\end{array}$ & $\begin{array}{l}\text { Men }(n=808 ; \\
33.6 \%)\end{array}$ & $p$ \\
\hline Age (mean \pm SD) & $32.9 \pm 7.9$ & $32.3 \pm 8.0$ & .796 \\
Years of education & & & \\
Basic school (9 years) & $305(20.1 \%)$ & $141(18.5 \%)$ & .407 \\
Secondary (12 years) & $673(44.5 \%)$ & $361(47.3 \%)$ & \\
University & $536(35.4 \%)$ & $262(34.3 \%)$ & \\
Work status & & & \\
$\quad$ Student & $260(16.3 \%)$ & $138(17.1 \%)$ & .001 \\
Employed & $1087(68.2 \%)$ & $587(72.9 \%)$ & \\
$\quad$ Not employed & $247(15.5 \%)$ & $80(9.9 \%)$ & \\
Income per month & & & \\
No income & $407(25.8 \%)$ & $183(22.8 \%)$ & $<.001$ \\
$\quad<750 €$ & $555(35.1 \%)$ & $140(17.5 \%)$ & \\
$750-1500 €$ & $463(29.3 \%)$ & $367(45.8 \%)$ & \\
$>$ 1501€ & $83(5.2 \%)$ & $57(7.1 \%)$ & \\
Not provided & $71(6.7 \%)$ & $54(4.5 \%)$ & \\
Currently involved in a & $1020(63.9 \%)$ & $537(66.5 \%)$ & .216 \\
relationship & & & \\
\hline
\end{tabular}

of the participants were not married but were currently in a relationship. The large majority of the participants identified as heterosexual (98.9\%). We excluded participants who described themselves as homosexual because, at the time of data collection, the use of assisted reproduction techniques in Portugal was exclusive to heterosexual couples who were married or had been cohabiting for longer than two years. As such, information on fertility and childbearing intentions may have been bounded to this condition.

\section{Childbearing intentions}

Approximately $95.5 \%$ of the participants in the study reported the desire to have children in the future, and $61.7 \%$ reported that having children in the future would contribute positively to their life satisfaction $(\mathrm{M}=3.67, \mathrm{SD}=.98)$. Differences were found between men and women $(\mathrm{M}=3.53, \mathrm{SD}=1.03$ and $\mathrm{M}=3.74, \mathrm{SD}=.95$, respectively $)$, but they were relatively small (Cohen's $\mathrm{d}=0.2$ ).

\section{Desired and planned children in the future}

Approximately 36 (4.6\%) men and $70(4.4 \%)$ women reported they did not want to have children in the future. Most participants reported wanting to have two children in the future $(N=1282,53.8 \%)$. Men and women did not differ regarding the number of children they desired $\left(X_{3}^{2}=5.68, p=.128\right)$. Our results also showed that the participants planned fewer children $(M=1.29, S D=0.95)$ than they desired to have $(M=1.94, S D=.85 ; t=35.06$, $p<0.001$ ) (see Fig. 1). This discrepancy was significantly higher for men $\left(F_{1,2345}=15.85, p<0.001\right)$, for participants with lower education levels $\left(F_{2,2221}=167.16\right.$, $p<0.001$ ), and for the participants who were professionally active or unemployed compared to those who were students $\left(F_{2,2339}=68.73, p<0.001\right)$. The discrepancy between the number of desired and number of planned children was also significant between age groups $\left(F_{2,2344}=326.77, p<.0 .001\right)$. Participants up to 25 years old reported the smallest discrepancy $(\mathrm{M}=.17$, $\mathrm{SD}=0.68$ ), while the oldest group (above 35 years old) reported the highest discrepancy $(\mathrm{M}=1.13, \mathrm{SD}=0.98)$.

\section{Ideal and planned age to have children}

The participants considered 29.20 years as the ideal age to have a first child $(\mathrm{SD}=2.8$ ), but most planned on having their first child by the age of 32.84 years $(\mathrm{SD}=4.80)$. This discrepancy was statistically significant $\left(\mathrm{F}_{1,1706}=1243.31, p<0.001\right)$ and was not different between men and women $\left(\mathrm{F}_{1,1705}=.68, p=.409\right)$.

Differences between the ideal age and the planned age for a first child were found according to all three education levels of the groups $\left(\mathrm{F}_{2,2494}=14,83, p<0.001\right)$, with the participants having 9 years or less of education showing the steepest discrepancy $(M=5.18 \mathrm{SD}=4.83)$ 

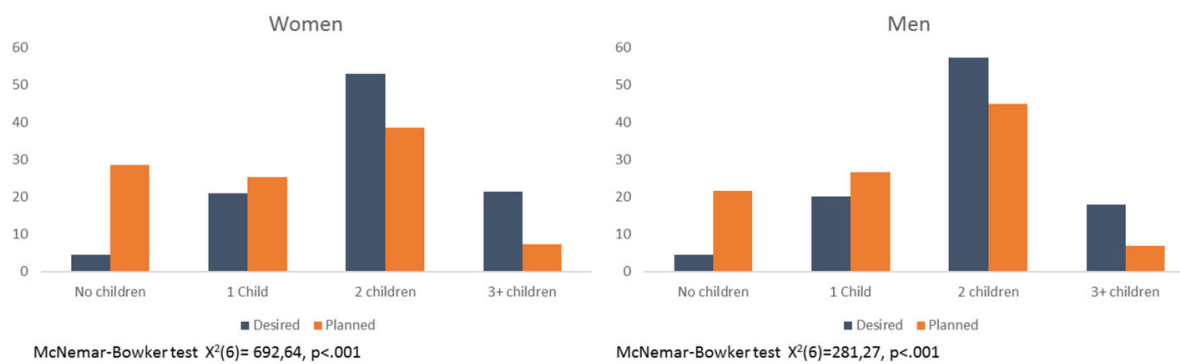

Fig. 1 Discrepancy between the number of desired and number of planned children. Values are percentage of participants in each category

compared to those who had completed secondary education $(M=3.14 ; S D=4.10)$ or university education $(M=3.69 ; S D=3.94)$. This discrepancy was also significantly different across the four levels of income $\left(\mathrm{F}_{3,1242}=18,54, p<0.001\right)$ and increased in significance as income level increased. Finally, the discrepancy was also significant according to professional status $\left(\mathrm{F}_{2,1700}=147.97, p<0.001\right)$, with students reporting the lowest gap $(\mathrm{M}=0.64, \mathrm{SD}=1.80)$ and professionally active individuals reporting the highest gap $(M=4.68$, $\mathrm{SD}=4.08)$. These results are presented in Table 2.

\section{Motives for parenthood and factors affecting childbearing decisions}

Figures 2 and 3 display, respectively, the most important motives for parenthood and the main factors affecting childbearing decisions.

For both men and women, the most valued motives for parenthood were related to personal fulfilment $(M=3.85, S D=0.98)$ and to the couple's relationship

Table 2 Differences between ideal and planned age for childbearing

\begin{tabular}{lllll}
\hline & Ideal age & Planned age & Difference & $p$ \\
\hline Gender & & & & \\
Men & $30.11 \pm 3.05$ & $33.86 \pm 4.91$ & -3.76 & $<.001$ \\
Women & $28.70 \pm 2.57$ & $32.28 \pm 4.64$ & -3.58 & $<.001$ \\
Age groups & & & & \\
18-25 & $28.28 \pm 2.62$ & $28.92 \pm 2.88$ & -0.64 & $<.001$ \\
26.35 & $29.30 \pm 2.59$ & $32.38 \pm 2.81$ & -3.08 & $<.001$ \\
$>36$ & $30.10 \pm 2.83$ & $38.72 \pm 4.11$ & -8.62 & $<.001$ \\
Education & & & & $<.001$ \\
9 years & $28.40 \pm 2.84$ & $33.58 \pm 5.20$ & -5.18 & $<.001$ \\
12 & $28.80 \pm 2.56$ & $31.94 \pm 6.67$ & -3.14 & $<.001$ \\
University & $29.79 \pm 2.94$ & $33.48 \pm 4.34$ & -3.69 & $<.001$ \\
Professional status & & & & -0.64 \\
Student & $28.65 \pm 2.86$ & $29.29 \pm 3.07$ & -0.64 & \\
Unemployed & $29.36 \pm 2.84$ & $34 . .03 \pm 4.73$ & -3.58 & $<.68$ \\
Active & $29.36 \pm 2.65$ & $32.95 \pm 4.60$ & -4.681 \\
\hline
\end{tabular}

$(M=3.88, S D=0.95)$. Similarly, the stability of a couple's relationship was the most important factor affecting childbearing decisions $(M=4.21, S D=0.79)$ compared to financial stability $(M=3.80, S D=0.98)$ and the availability of family support $(M=3.86, S D=0.94)$.

\section{Knowledge of fertility and assisted reproduction techniques \\ Knowledge of fertility and infertility risks}

A set of 24 statements referring to human fertility knowledge and infertility risk factors was presented to the participants, who were asked to score each statement as correct or incorrect. The results revealed that the participants generally had poor knowledge of fertility, as they only scored approximately half of the statements correctly $(M=11.50, S D=3.97)$. Women scored more statements correctly than men (11.8 vs. $10.8, t=-5.94$, $p<0.001)$. Significant differences in the number of correct answers were found according to age group $\left(\mathrm{F}_{2,2381}=23.82, \quad p<0.001\right)$, education level $\left(\mathrm{F}_{2,2256}=88.72, p<0.001\right)$, professional status

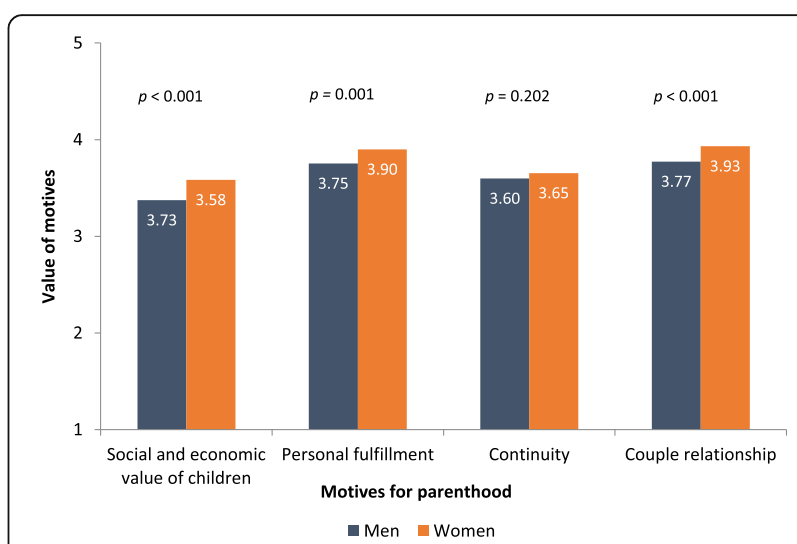

Fig. 2 Motives for parenthood for men and women. Motives were defined as Social and economic value of children, such as social importance of parenthood, economical support for parents in the future; Personal fulfilment, as contributing for meaning of own life; Continuity, such as importance of genetic continuity and family lineage. Participants rated each motive from 1 to 5 . T tests for independent samples were conducted to compare value of motives between men and women 


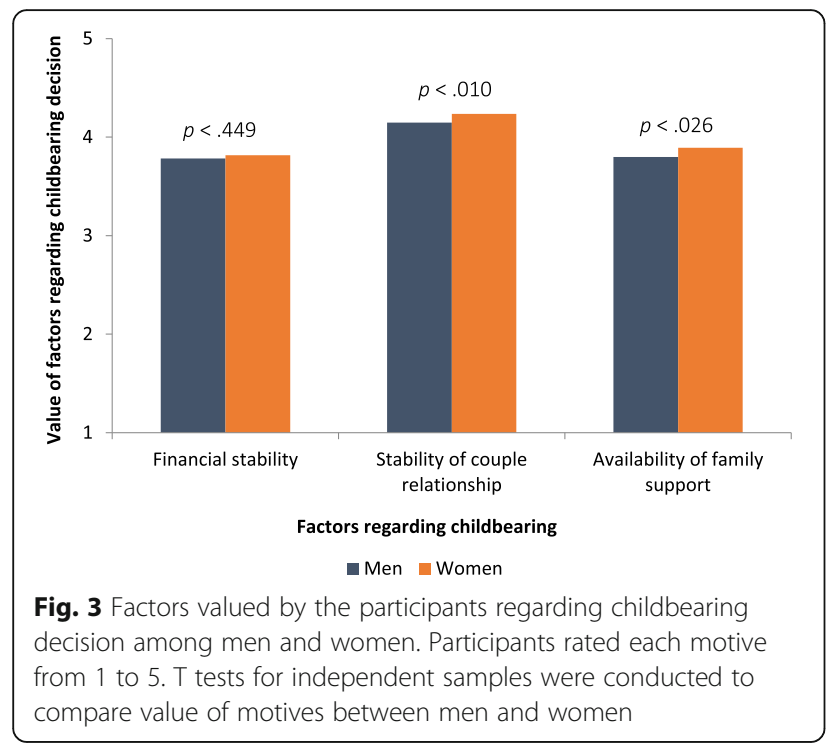

$\left(\mathrm{F}_{2,2376}=20.60, p<0.001\right)$, and income level $\left(F_{3,1855}=11.46, p<0.001\right)$, although in all cases the differences were small. Figure 4 reports the number of correct answers given per group of participants.

\section{Knowledge regarding chances of achieving pregnancy spontaneously and after undergoing one cycle of assisted reproduction}

The participants tended to overestimate their changes of achieving pregnancy, and no differences were found between men and women $(\chi 2=3.71, p=.295)$. Approximately $68.7 \%$ of the participants reported that a healthy couple has a greater than $50 \%$ chance of becoming pregnant each month, and only $9.3 \%$ reported odds of achieving pregnancy per month of less than $25 \%$.

The participants also overestimated the success rates of ART. Approximately $45.5 \%$ of the participants reported that more than half of couples would achieve pregnancy after the first ART cycle.

\section{Gathering information on fertility and infertility risks Use and perceived usefulness of sources of information on fertility and infertility risks}

The participants were assessed regarding the sources of information they typically used and on the perceived usefulness of each source. Figure 5 displays the results for these two categories.

The results showed that few of the participants had used the sources of information that they perceived as the most useful, such as doctors. The main information sources that were used were websites containing medical information and newspapers and magazines, and these were perceived as only moderately useful. Medical doctors, who were considered very useful sources of information, were used by less than $30 \%$ of the participants.

\section{Discussion of fertility issues with doctors}

Only $18.0 \%$ of the participants reported that they had discussed fertility issues during appointments with medical doctors. Of these, $34.6 \%$ participants reported discussing these issues with their general practitioner, and $48.1 \%$ reported discussing them with their gynaecologist or fertility doctor. When fertility issues were discussed during medical appointments, the participants reported that the topic was discussed often (33.3\%), sometimes (46.6\%) or almost never (12.6\%). In most situations, the

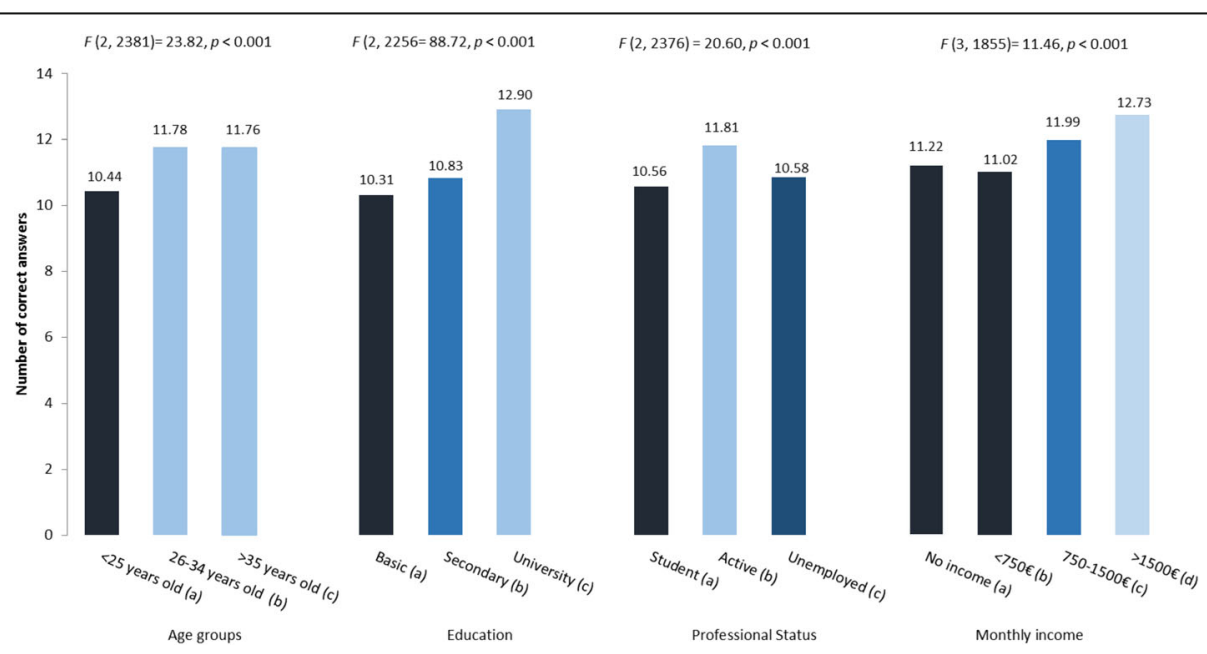

Fig. 4 Number of correct answers per subgroup according to age, education, professional status and monthly income. Group comparisons: Age groups: $\mathrm{a}<\mathrm{b},(p<0.001) ; \mathrm{a}<\mathrm{c},(p<0.001) ; \mathrm{b}=\mathrm{c},(p=0.999)$. Education: $\mathrm{a}<\mathrm{b}(p<0.049), \mathrm{a}<\mathrm{c}(p<0.001) ; \mathrm{b}<\mathrm{c}(p=0.999)$. Professional status: $\mathrm{a}<\mathrm{b}(p<0.001), \mathrm{a}<\mathrm{c}(p<0.999) ; \mathrm{b}>\mathrm{c}(p<0.001)$. Monthly income: $\mathrm{a}=\mathrm{b}(p=0.990), \mathrm{a}=\mathrm{c}(p<0.082) ; \mathrm{a}<\mathrm{d}(p=0.004) ; \mathrm{b}<\mathrm{c}$ $(p<0.001) ; b<d(p<0.001) ; c=d(p=.252)$ 


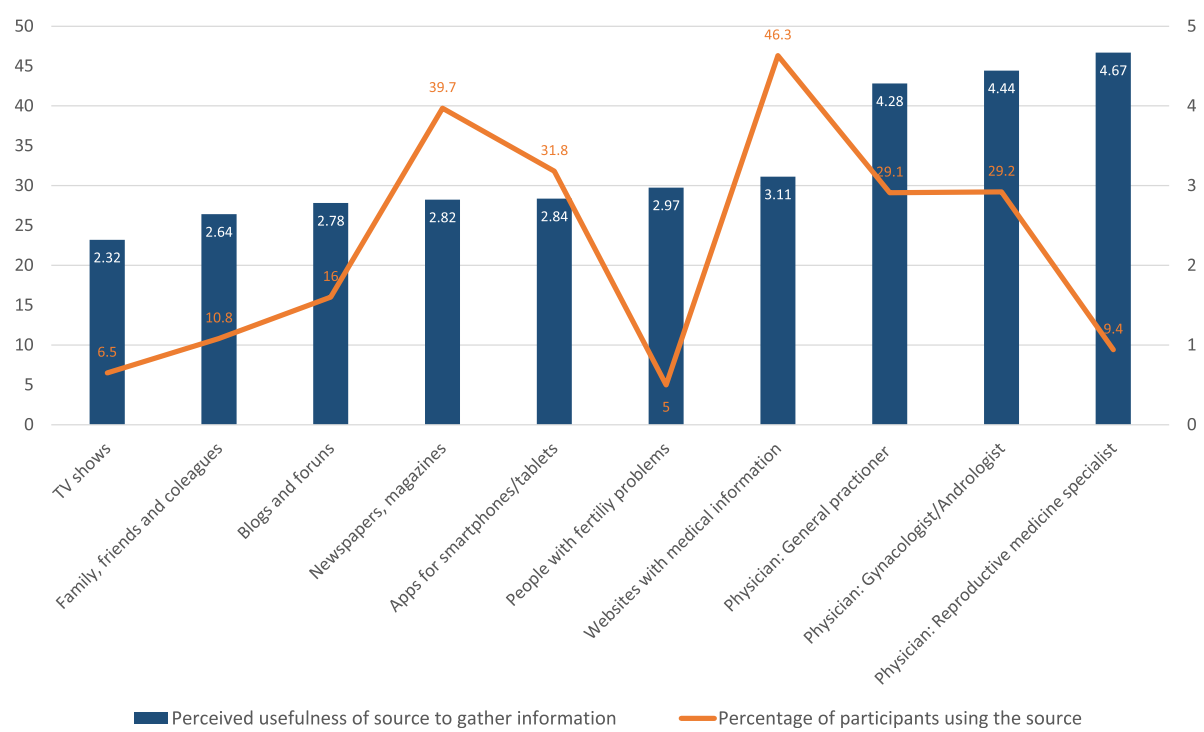

Fig. 5 Information sources typically used by the participants and their perceived usefulness regarding fertility and reproductive health. The blue columns refer to the perceived usefulness of each source of information for gathering knowledge on fertility. The orange line refers to the percentage of participants who actually used each listed information source to gather knowledge on fertility

topic was raised by the patients (71.5\%) compared to by a doctor $(28.5 \%)$.

\section{Discussion}

The present study described childbearing intentions of, knowledge of fertility possessed by and information gathering sources used by a childless Portuguese population. To the best of our knowledge, this is the only large-scale study that has assessed fertility knowledge in a representative national sample using a door-to-door recruitment procedure, overcoming the limitations of previous studies that collected data using online methods and mainly recruited university students, threatening the generalizability of this conclusions to the general population.

Concordant with previous studies, in the current work, the majority of participants planned to have children in the future, although there was a discrepancy between their expressed desires and their plans. The majority of participants in our sample wanted to have two children, although a significant proportion did not make plans to accomplish this target. This discrepancy was more pronounced in the older population, probably because of the reduced time left to this population for the completion of reproductive plans. Additionally, conditions such as lack of relationship stability, financial stability or family support were associated with higher discrepancies. The postponement of parenthood relative to what is desired may also contribute to the perception that the ideal family size will not be reachable, even though our participants were not aware that fertility declines as women age. Other studies have also shown that there is a considerable difference between intended and realized family size; this fertility gap may be up to half a child among European countries [1, 12].

Our results also highlighted that, in general, both men and women are poorly informed about fertility and infertility risk factors. Indeed, the participants scored less than half of the statements on the questionnaire correctly, which is in accordance with other findings, although the use of different items to evaluate fertility knowledge prevents comparisons to published results.

Our results suggest that education is positively correlated with fertility knowledge, in accordance with other studies [11, 17]. However, in our study, neither the women nor the men were sufficiently aware of the agerelated decline that occurs in female fecundity, and both the women and the men had optimistic perceptions of women's chances of becoming pregnant. These results are in agreement with previous studies, including one that evaluated university students in Sweden [1]. Our sample included people with low education levels, unlike previous studies, which have predominantly included university students or people attending fertility clinics, who tend to be more informed on these subjects. The low fertility knowledge of this less educated population may reflect a general health illiteracy and emphasizes the need to develop strategies to increase the information available to such populations.

Fertility knowledge also varied in terms of sociodemographic variables, with those who had higher income, those who worked, those who were older and those who had greater education being better informed. The lower fertility knowledge exhibited by the participants 
who were younger than 25 may have reflected the inclusion of undergraduate students, as this population is generally not making childbearing decisions or seeking fertility information.

Finally, the lack of knowledge exhibited by the participants may have resulted from the sources of information that Portuguese men and women tend to use. Indeed, although the participants considered general practitioners and fertility specialists the most useful and trustworthy sources of information, they tended to use other sources instead. In addition, we also verified that general practitioners seldom took the initiative to provide information on fertility and infertility risks.

A major strength of the present work was the method used for sample recruitment. A door-to-door method was employed, which allowed the collection of data from a representative Portuguese population. This method enabled us to recruit participants regardless of their ability to access the internet and regardless of whether they were students, which are major limitations of previous studies on this topic $[1,9,10]$. As a consequence, participants with several levels of education, incomes and professional statuses were included in the study. Another important strength of our study was the inclusion of large numbers of both men and women. Indeed, most other studies have focused predominantly on women and have not evaluated men's knowledge on fertility. This is linked to another important strength of the study, which was the assessment of the study group's knowledge of specific risk factors for male infertility and the evaluation of gender differences with regard to knowledge and the sources of information used. Finally, the evaluation of the main sources of information used by men and women was another important strength, as it may contribute to the development of specific strategies to increase fertility knowledge in populations of reproductive age.

Albeit these strengths, it is important to note that the recruitment strategy that was used may have an influence in study results. Indeed, it has been documented that random route strategy may have some bias in the representation of some participants' variables [16], namely by overrecruiting participants from subgroups of the population (in general, younger or older, unemployed) [18]. However, we believe that the inclusion criteria (age range, childlessness) and the recruitment during a large period of the day and during both weekdays and weekends, has highly reduced this bias.

\section{Implications for public health decisions and information campaigns}

As the provision of information regarding fertility is essential for helping those who wish to become parents to make qualified decisions on when to start having children [12], there is a real need to work with general practitioners, particularly those working in family planning, to empower them to provide adequate fertility information to every childless patient.

\section{Conclusion}

Men and women have little information on the factors that affect their fertility, namely on modifiable behavioural risk factors. This lack of information may not only prevent individuals from correcting their behaviour in order to protect their fertility but also from requiring additional information on this topic from the most relevant and trustworthy sources of information. The provision of information on fertility is of uttermost importance in order to promote informed decisions on planning childbearing.

\section{Abbreviations}

ANOVA: Analysis of variance; ART: Assisted reproductive technology; IBM SPSS: Statistical Package for Social Sciences

\section{Acknowledgements}

We acknowledge the financial support of Merck Serono, S.A.

\section{Funding}

MM-R holds a postdoctoral grant from the Portuguese Foundation for Science and Technology (FCT-SFRH/BPD/87514/2012). CM holds a doctoral grant from the Portuguese Foundation for Science and Technology (FCTSFRH/BD/84677/2012). Merck Serono, SA, funded the data collection that was performed by Keypoint, SA.

Merck Serono SA performed a scientific review of the publication but the views and opinions described in the publication are those of the authors.

\section{Availability of data and materials}

The datasets generated and/or analyzed during the current study are not publicly available due to the reason that there is no informed consent by the subjects that the data can be shared.

\section{Authors' contributions}

TAS was involved in conception and design of the study, in the interpretation of the data and in drafting/revising and giving final approval of the manuscript. CM was involved in conception and design of the study and in revising and giving final approval of the manuscript. AM was involved in conception and design of the study, in data collection, interpreting the data and giving final approval of the manuscript. MMR was involved in conception and design of the study, in the data analysis, in the interpretation of the data and in drafting/ revising and giving final approval of this manuscript.

Ethics approval and consent to participate

The participants were informed about the purposes and procedures of the data collection, and the potential risks and benefits of the study. It was explained that participation would be voluntary and the data is anonymous. Oral informed consent was obtained from each participant. To strengthen confidentiality, participants were identified only through numerical codes.

Consent for publication

Not applicable.

Competing interests

TAS has received honoraria for participating in advisory boards for Merck Serono, S.A.. MMR and TAS have received speaking fees from Merck Serono S.A. Other authors declare that they have no competing interests. 


\section{Publisher's Note}

Springer Nature remains neutral with regard to jurisdictional claims in published maps and institutional affiliations.

\section{Author details}

'Faculty of Medicine, University of Coimbra, Rua Larga, 3004-504 Coimbra, Portugal. ${ }^{2}$ Centro Hospitalar Universitário de Coimbra, Av. Bissaya Barreto e Praceta Prof. Mota Pinto, 3000-075 Coimbra, Portugal. ${ }^{3}$ CINEICC - Cognitive and Behavioural Centre for Research and Intervention, Faculty of Psychology and Educational Sciences, University of Coimbra, Rua do Colégio Novo, 3001-802 Coimbra, Portugal. ${ }^{4}$ KeyPoint, Edifício Miraflores Premium, Al. Fernão Lopes, n¹6, $6^{\circ}$ Andar, 1495-190 Miraflores, Portugal.

Received: 22 February 2017 Accepted: 25 July 2017

Published online: 04 August 2017

\section{References}

1. Lampic C, Svanberg AS, Karlström P, Tydén T. Fertility awareness, intentions concerning childbearing, and attitudes towards parenthood among female and male academics. Hum Reprod. 2006:21:558-64.

2. Bretherick KL, Fairbrother N, Avila L, Harbord SH, Robinson WP. Fertility and aging: do reproductive-aged Canadian women know what they need to know? Fertil Steril. 2010;93:2162-8.

3. Bunting $L$, Boivin J. Knowledge about infertility risk factors, fertility myths and illusory benefits of healthy habits in young people. Hum Reprod. 2008; 23:1858-64.

4. Virtala A, Vilska S, Huttunen T, Kunttu K. Childbearing, the desire to have children, and awareness about the impact of age on female fertility among Finnish university students. Eur J Contracept Reprod Health Care. 2011;16: 108-15.

5. Garcia D, Vassena R, Prat A, Vernaeve V. Increasing fertility knowledge and awareness by tailored education: a randomized controlled trial. Reprod BioMed Online. 2016:32:113-20.

6. Skoog Svanberg A, Lampic C, Karlstrom PO, Tyden T. Attitudes toward parenthood and awareness of fertility among postgraduate students in Sweden. Gend Med. 2006:3:187-95.

7. Lundsberg LS, Pal L, Gariepy AM, Xu X, Chu MC, Illuzzi JL. Knowledge, attitudes, and practices regarding conception and fertility: a populationbased survey among reproductive-age United States women. Fertil Steril. 2014;101:767-74

8. Hashiloni-Dolev Y, Kaplan A, Shkedi-Rafid S. The fertility myth: Israeli students' knowledge regarding age-related fertility decline and late pregnancies in an era of assisted reproduction technology. Hum Reprod. 2011:26:3045-53.

9. Daniluk JC, Koert E. Childless Canadian men's and women's childbearing intentions, attitudes towards and willingness to use assisted human reproduction. Hum Reprod. 2012;27:2405-12.

10. Sabarre KA, Khan Z, Whitten AN, Remes O, Phillips KP. A qualitative study of Ottawa university students' awareness, knowledge and perceptions of infertility, infertility risk factors and assisted reproductive technologies (ART). Reprod Health. 2013;10:41.

11. Daniluk JC, Koert E, Cheung A. Childless women's knowledge of fertility and assisted human reproduction: identifying the gaps. Fertil Steril. 2012;97:420-6.

12. Schmidt L, Sobotka T, Bentzen JG, Nyboe Andersen A. Demographic and medical consequences of the postponement of parenthood. Hum Reprod Update. 2012;18:29-43.

13. Sobotka T, Lutz W. Misleading policy messages derived from the period TFR: Should we stop using it? Comp Popul Stud. 2010;35:665-96.

14. Mills M, Rindfuss RR, McDonald P, te Velde E. Why do people postpone parenthood? Reasons and social policy incentives. Hum Reprod Update. 2011;17:848-60

15. Bauer JJ. Selection errors of random route samples. Sociol Methods Res. 2014;43:519-44

16. Rada V, Martín V. Random route and quota sampling: Do they offer any advantage over probably sampling methods? Open J Stat. 2014;4:391-401.

17. Bunting L, Tsibulsky I, Boivin J. Fertility knowledge and beliefs about fertility treatment: findings from the International Fertility Decision-making Study. Hum Reprod. 2013:28:385-97.

18. Hoffmeyer-Zlotnik JHP. New sampling designs and the quality of data. In: Ferligoj A, Mrvar A, editors. Developments in Applied Statistics. Ljubljana: FDV; 2003. pp. 205-217.

\section{Submit your next manuscript to BioMed Central and we will help you at every step:}

- We accept pre-submission inquiries

- Our selector tool helps you to find the most relevant journal

- We provide round the clock customer support

- Convenient online submission

- Thorough peer review

- Inclusion in PubMed and all major indexing services

- Maximum visibility for your research

Submit your manuscript at www.biomedcentral.com/submit 